\title{
Is obesity a disease? - the evolving concepts, cancer paradox and association with improved cancer immunotherapy efficacy
}

\author{
Monica Cheng, Richard B. Gunderman \\ Department of Radiology and Imaging Sciences, Indiana University School of Medicine, Indianapolis, Indiana, USA \\ Correspondence to: Monica Cheng. Indiana University School of Medicine, 702 Barnhill Drive, Indianapolis, Indiana 46202, USA. Email: mocheng@iu.edu; \\ monicacheng520@gmail.com. \\ Provenance and Peer Review: This article was commissioned by the Editorial Office, Hepatobiliary Surgery and Nutrition. The article did not undergo external \\ peer review. \\ Comment on: Wang Z, Aguilar EG, Luna JI, et al. Paradoxical effects of obesity on T cell function during tumor progression and PD-1 checkpoint \\ blockade. Nat Med 2019;25:141-51.
}

Submitted Nov 13, 2019. Accepted for publication Nov 28, 2019.

doi: 10.21037/hbsn.2019.11.35

View this article at: http://dx.doi.org/10.21037/hbsn.2019.11.35

Obesity represents a growing health problem in the United States and worldwide, with a prevalence that has doubled since 1980 (1). In the United States, 70\% of adults and $37 \%$ of adolescents are overweight or obese. The chronic health implications of obesity make it a public health issue with significant economic ramifications. By promoting an altered whole-body physiology, obesity increases the risk for chronic diseases including diabetes, cardiovascular disease, and cancer (2).

To address the accelerating rate of obesity in the United States, the American Medical Association (AMA) House of Delegates took the stance of defining obesity as a disease state in $2013(3,4)$. Recognizing obesity as a disease has the potential to improve access to treatment and stimulate the advancement of novel therapies. However, providing a disease label has other important consequences. Medicalizing obesity gives the status of "disease" to tens of millions of adults and children in the United States. It runs the risk of relying on costly medical treatment while neglecting preventive public policy measures to address the underlying societal determinants of obesity (5). Moreover, historically our classifications of health, disease, and obesity have been riddled with ambiguities.

Our perception of disease is shaped by sociocultural contexts and evolving health expectations, diagnostic capabilities, and socioeconomic driving forces. Osteoporosis, for example, had been previously considered an inevitable part of normal aging but was recognized as a disease by WHO in 1994 (6). By contrast, in the early $20^{\text {th }}$ century, homosexuality was considered to be an endocrine disorder and later on an organic mental disorder before finally in 1974 becoming de-pathologized and removed from the Diagnostic and Statistical Manual IV. Obesity, on the other hand, is regarded as the product of an "obesogenic" environment consisting of commercially driven high caloric diets and reduced physical activity in the context of low health literacy and food deserts. The World Obesity Federation further defines obesity as a "chronic, relapsing, progressive, disease process" that requires intervention (3).

The lack of accurate metrics to classify obesity calls into question the utility of defining obesity as a disease in order to improve health outcomes. Efforts to define obesity are complicated by the imperfect measures available to classify the condition. The most widely accepted and established measure of obesity is the body mass index (BMI) scale, which was developed by Adolphe Quetelet in the late 1800s (7). The BMI scale, however, suffers from important limitations including failure to account for variations in body composition; measurements tend to overestimate adiposity in athletes who have higher lean body mass and underestimate in the elderly who have diminished lean mass (8). Other less universal methods to measure body composition include waist circumference, waist to hip or height ratio, skin fold thickness, and dual energy X-ray absorptiometry.

The challenges of classifying obesity using BMI are further illustrated by its nuanced role in cancer therapeutics and survival outcomes. Although obesity appears to promote tumorigenesis particularly in hormone receptor-positive breast cancer in post-menopausal women, high BMI also 
has a protective role in other cancers-a phenomenon known as the "obesity paradox" (9-11). Such findings may be partly related to the deleterious effects of cachexia, but also suggest the need for tools beyond BMI to characterize the body habitus. In oncology, body composition analysis is a more accurate method of quantifying muscle mass and adiposity. Martin and colleagues found that BMI greater than $25 \mathrm{~kg} / \mathrm{m}^{2}$ is associated with a survival advantage in GI and respiratory tract tumors, but this protective effect of obesity was eliminated in the presence of a low fat-free mass index, or sarcopenia (12). Sarcopenia visualized on CT imaging is significantly correlated with diminished overall survival across tumors of all stages due to greater rates of surgical complications, treatment toxicity, and markers of systemic inflammation (13). The nuanced role of obesity in oncology underscores the importance of accurately defining the body habitus to help guide tailored intervention in the era of precision medicine.

In a recent issue of Nature Medicine, Wang et al. [2019] demonstrated that checkpoint blockade with PD-1/PDL1 inhibitors harnesses the paradoxical effect of obesity in order to enhance tumor response to immunotherapy (14). While obesity promotes a meta-inflammatory state in which leptin is associated with increased PD-1 expression and T cell dysfunction, these features can be successfully targeted by $\mathrm{PD}-(\mathrm{L}) 1$ checkpoint inhibition and therefore serve as a paradoxically positive prognostic factor. These findings are supported by other reports that link obesity with improved overall survival and progression-free survival in patients with metastatic melanoma, bladder cancer, colorectal cancer, lung cancer, and renal cell carcinoma treated with targeted or immunotherapy (15-21). Importantly, immune checkpoint blockade has achieved augmented survival outcomes for only a subset of patients, creating a critical need to identify predictive biomarkers to guide patient selection for treatment. New studies further indicate that the gut microbiome may also modulate cancer response to immune checkpoint inhibitor therapy and is an area of active research (22-26).

Obesity also impacts health in indirect ways. In radiology, for example, image quality and acquisition are compromised by the body habitus of an obese patient. The increased soft tissue mass in obesity diminishes the signal-to-noise ratio and complicates the radionuclide dosimetry calculations used in PET imaging (27). Since radionuclide dosimetry is dependent on weight $(\mathrm{mCi} / \mathrm{kg})$, obese patients who exceed the maximum allowed dose may require tailored scans using the highest field gamma cameras and imaging for longer durations in order to maximize counts.

The AMA decision to declare obesity as a disease is a well-intentioned effort to legitimize the condition and shift public discourse from blame and stigmatism to medical therapy. However, disease implies the need for costly treatment in the form of drugs, medical technologies, and bariatric surgery. To call obesity a disease is to furthermore ignore the limitations of obesity measurement tools that tremendously impact management and prognosis (5). Obesity may be better characterized as a multidimensional risk factor that requires social and policy reform as well as continued efforts to elucidate the components of the body habitus in order to inform preventive and therapeutic efforts, including those that harness the paradoxical effect of obesity to enhance immunotherapy response.

\section{Acknowledgments}

Funding: None.

\section{Footnote}

Conflicts of Interest: All authors have completed the ICMJE uniform disclosure form (available at https://hbsn. amegroups.com/article/view/10.21037/hbsn.2019.11.35/coif). The authors have no conflicts of interest to declare.

Ethical Statement: The authors are accountable for all aspects of the work in ensuring that questions related to the accuracy or integrity of any part of the work are appropriately investigated and resolved.

Open Access Statement: This is an Open Access article distributed in accordance with the Creative Commons Attribution-NonCommercial-NoDerivs 4.0 International License (CC BY-NC-ND 4.0), which permits the noncommercial replication and distribution of the article with the strict proviso that no changes or edits are made and the original work is properly cited (including links to both the formal publication through the relevant DOI and the license). See: https://creativecommons.org/licenses/by-nc$\mathrm{nd} / 4.0 \%$.

\section{References}

1. Swinburn BA, Kraak VI, Allender S, et al. The Global syndemic of obesity, undernutrition, and climate change: The Lancet Commission report. Lancet 2019; 393:791-846. 
2. Curry SJ, Krist AH, Owens DK, et al. Behavioral weight loss interventions to prevent obesity-related morbidity and mortality in adults: US Preventive Services Task Force recommendation statement. JAMA 2018;320:1163-71.

3. Bray GA, Kim KK, Wilding JPH. Obesity: a chronic relapsing progressive disease process. A position statement of the World Obesity Federation. Obes Rev 2017;18:715-23.

4. Kyle TK, Dhurandhar EJ, Allison DB. Regarding Obesity as a Disease: Evolving policies and their implications. Endocrinol Metab Clin North Am 2016;45:511-20.

5. Flegal KM, Ioannidis JPA, Doehner W. Flawed methods and inappropriate conclusions for health policy on overweight and obesity: the Global BMI Mortality Collaboration metaanalysis. J Cachexia Sarcopenia Muscle 2019;10:9-13.

6. Scully JL. What is a disease? EMBO Rep 2004;5:650-3.

7. Machann J, Horstmann A, Born M, et al. Diagnostic imaging in obesity. Best Pract Res Clin Endocrinol Metab 2013;27:261-77.

8. Park Y, Peterson LL, Colditz GA. The Plausibility of Obesity Paradox in Cancer-Point. Cancer Res 2018;78:1898-903.

9. Shachar SS, Williams GR. The Obesity Paradox in Cancer-Moving beyond BMI-Response. Cancer Epidemiol Biomarkers Prev 2017;26:981.

10. Greenlee H, Unger JM, LeBlanc M, et al. Association between Body Mass Index and Cancer Survival in a Pooled Analysis of 22 Clinical Trials. Cancer Epidemiol Biomarkers Prev 2017;26:21-9.

11. Lam VK, Bentzen SM, Mohindra P, et al. Obesity is associated with long-term improved survival in definitively treated locally advanced non-small cell lung cancer (NSCLC). Lung Cancer 2017;104:52-7.

12. Martin L, Birdsell L, Macdonald N, et al. Cancer cachexia in the age of obesity: skeletal muscle depletion is a powerful prognostic factor, independent of body mass index. J Clin Oncol 2013;31:1539-47.

13. Lenchik L, Boutin RD. Sarcopenia: beyond muscle atrophy and into the new frontiers of opportunistic imaging, precision medicine, and machine learning. Semin Musculoskelet Radiol 2018;22:307-22.

14. Wang Z, Aguilar EG, Luna JI, et al. Paradoxical effects of obesity on $\mathrm{T}$ cell function during tumor progression and PD-1 checkpoint blockade. Nat Med 2019;25:141-51.

15. McQuade JL, Daniel CR, Hess KR, et al. Association of body-mass index and outcomes in patients with metastatic melanoma treated with targeted therapy, immunotherapy, or chemotherapy: a retrospective, multicohort analysis.
Lancet Oncol 2018;19:310-22.

16. Naik GS, Waikar SS, Johnson AEW, et al. Complex inter-relationship of body mass index, gender and serum creatinine on survival: exploring the obesity paradox in melanoma patients treated with checkpoint inhibition. J Immunother Cancer 2019;7:89.

17. Donnelly DA, Bajaj S, Zhong J, et al. The relationship between obesity and immunotherapy: It's complicated. J Clin Oncol 2019;37:9562.

18. Renfro LA, Loupakis F, Adams RA, et al. Body mass index is prognostic in metastatic colorectal Cancer: pooled analysis of patients from first-line clinical trials in the ARCAD database. J Clin Oncol 2016;34:144-50.

19. Martini DJ, Shabto JM, Liu Y et al. Body mass index (BMI) and toxicities and association with clinical outcomes (CO) in metastatic renal cell carcinoma (mRCC) patients (pts) treated with cabozantinib (cabo). J Clin Oncol 2019;37:613.

20. Lalani AA, Xie W, Flippot R, et al. Impact of body mass index (BMI) on treatment outcomes to immune checkpoint blockade (ICB) in metastatic renal cell carcinoma (mRCC). J Clin Oncol 2019;37:566.

21. Cortellini A, Bersanelli M, Buti S, et al. A multicenter study of body mass index in cancer patients treated with anti-PD-1/ PD-L1 immune checkpoint inhibitors: when overweight becomes favorable. J Immunother Cancer 2019;7:57.

22. Gopalakrishnan V, Helmink BA, Spencer CN, et al. The influence of the gut microbiome on cancer, immunity, and cancer immunotherapy. Cancer Cell 2018;33:570-80.

23. Shigematsu Y, Inamura K. Gut microbiome: a key player in cancer immunotherapy. Hepatobiliary Surg Nutr 2018;7:479-80.

24. Yi M, Qin S, Chu Q, et al. The role of gut microbiota in immune checkpoint inhibitor therapy. Hepatobiliary Surg Nutr 2018;7:481-3.

25. Mima K, Baba H. The gut microbiome, antitumor immunity, and liver cancer. Hepatobiliary Surg Nutr 2019;8:67-8.

26. Hampton T. Gut microbes may shape response to cancer immunotherapy. JAMA 2018;319:430-1.

27. Uppot RN. Technical challenges of imaging \& imageguided interventions in obese patients. Br J Radiol 2018;91:20170931.

Cite this article as: Cheng M, Gunderman RB. Is obesity a disease?- the evolving concepts, cancer paradox and association with improved cancer immunotherapy efficacy. HepatoBiliary Surg Nutr 2020;9(2):247-249. doi: 10.21037/hbsn.2019.11.35 